\title{
Gamma-Ray-Attenuation used for Measuring the Moisture Content and Homogeneity of
} Porous Concrete

\author{
Nielsen, A. F.
}

Published in:

Building Science

Publication date:

1972

Document Version

Publisher's PDF, also known as Version of record

Link back to DTU Orbit

Citation (APA):

Nielsen, A. F. (1972). Gamma-Ray-Attenuation used for Measuring the Moisture Content and Homogeneity of Porous Concrete. Building Science, 7(4), 257-263.

\section{General rights}

Copyright and moral rights for the publications made accessible in the public portal are retained by the authors and/or other copyright owners and it is a condition of accessing publications that users recognise and abide by the legal requirements associated with these rights.

- Users may download and print one copy of any publication from the public portal for the purpose of private study or research.

- You may not further distribute the material or use it for any profit-making activity or commercial gain

- You may freely distribute the URL identifying the publication in the public portal

If you believe that this document breaches copyright please contact us providing details, and we will remove access to the work immediately and investigate your claim 
REPRINT

LABORATORIET FOR VARMEISOLERING

DANMARKS TEKNISKE HDJSKOLE

MEDDELELSE NR. 28

\section{Building Science}

PERGAMON PRESS Oxford - London - New York - Paris 


\title{
Gamma-Ray-Attenuation used for Measuring the Moisture Content and Homogeneity of Porous Concrete
}

\author{
A. F. NIELSEN*
}

\begin{abstract}
The method of gamma-ray-attenuation for the determination of moisture content has the advantage of being non-destructive and independent of temperature gradients in the material. It is also possible to check the homogeneity of specimens by this method. The Laboratory of Thermal Insulation has equipment with a $100 \mathrm{mCi} \mathrm{Am}^{241}$ source for measurements on porous concrete. The paper gives a survey of the theory for gamma-ray-attenuation and the calibration of the equipment including measured values found for this equipment. At the end some examples are given of measurements of homogeneity and moisture content for different specimens.
\end{abstract}

\section{INTRODUCTION}

EXPERIMENTAL investigation of moisture flow in porous materials has hitherto been difficult owing to lack of reliable non-destructive methods for determining the moisture distribution. However, measuring of gamma-ray-attenuation in the material has shown to be well suited for this purpose.

Gamma-ray-attenuation was used originally in soil physics for the determination of soil densities $[1,2,4]$, and can also be used to determine the water content. The measuring equipment to be used must be calibrated against the specific material in question by determining the moisture content by means of the drying and weighing method. When this is done the equipment is easy to operate and seems to give reliable results.

The equipment used at the Thermal Insulation Laboratory has been made specially for measuring the moisture content in porous concrete, and is also used to check the homogeneity of the specimens which will be used in the measurement of moisture flow under variable conditions. As the measurements of moisture flow will normally take place in the "wet" region ("wet" means that the material has a moisture content corresponding to relative humidities higher than 98 per cent, for porous concrete about 3 per cent vol.) the terms moisture and water will by synonymous in this paper. The greater part of the moisture in the material will be in the liquid phase.

* Thermal Insulation Laboratory, Technical University of Denmark.

\section{THEORY}

The attenuation of mono-energetic gammaradiation for a fixed source-detector distance is normally described by

$$
\ln N=\ln N_{0}-\mu \rho x
$$

where $N$ the intensity with absorbing material (counts/sec)

$N_{0}$ the intensity without absorbing material (counts/sec)

$\mu$ the absorption coefficient for the material $\left(\mathrm{cm}^{2} / \mathrm{g}\right)$

$\rho$ the density of the material $\left(\mathrm{g} / \mathrm{cm}^{3}\right)$

$x$ the thickness of the material sample (cm).

The absorption is caused by the Compton scattering, Compton absorption, the photoelectric effect and Raleigh scattering. The absorption for a mixture is given by

$$
\ln N=\ln N_{0}-(\mu \rho x)_{a}-(\mu \rho x)_{b}
$$

where $a$ the values for one material

$b$ the values for another material.

For a high counting rate it is necessary to correct for the resolution time of the instrument, and for a small counting rate it is necessary to correct for background radiation.

$$
N=\frac{C}{T-C \cdot \tau}-B
$$


where $N$ the correct counting rate (counts/sec)

$C$ the number of pulses (counts)

$T$ measured time (sec)

$\tau$ resolution time ( $\mathrm{sec} / \mathrm{counts}$ )

$B$ background radiation (counts/sec).

For the specimens used in the investigations, porous concrete, we get:

$\ln N=\ln N_{0}-(\mu \rho x)_{c}-(\mu \rho x)_{w}-(\mu \rho x)_{g}-(\mu \rho x)_{a}$

where $(\mu \rho x)=$ the material values for

$c$ porous concrete

$w$ water

$g$ glue

a acryl

In this formula, and later on in the paper, the intensities will always be corrected for resolution time and background.

\section{STATISTICS}

The decay of radioactive material is of a statistical character. Therefore one measurement with gammarays will not give the real value of density or water content, but it will be within certain limits from the real value. If we measure $\Delta N$ counts in time $\Delta t$ (which we suppose is free from errors), we know that the measured value is $\Delta N \pm \sigma$, where $\sigma$ is the standard derivation. It can be shown that

$$
\sigma=\sqrt{ }(\Delta N)
$$

The standard derivation gives 68 per cent probability that the measured value $\pm \sigma$ contains the real value. From equation (5) we find that for $10^{5}$ counts the "error" is $0 \cdot 31$ per cent, and for $10^{6}$ counts the "error" is 0.1 per cent. To attain a high degree of certainty, it is necessary to measure a large number of counts. For the measurements of moisture flow it is necessary to be sure that the moisture distribution will not be affected in the time it takes to make the measurements, as the specimens must be taken out of the test devices. We are using a fixed time of $1.38 \mathrm{~min}$ per measure. ment. With this value we find the standard derivation $\sigma$ for 5 vol. per cent water \pm 0.2 vol. per cent and for 60 vol. per cent water \pm 0.5 vol. per cent, where the calculation is made from equation (9), and the standard derivations from the parts of the equation are taken into account.

\section{EQUIPMENT}

The source and the detector are mounted on a steel plate. Between the source and the detector is a circular hole with a lift for the specimens. This mechanism makes it possible to measure at the same part of the specimen each time (accuracy about $0.5 \mathrm{~mm}$ ). Under the steel plate is the BASCinstrument (see figures 1 and 2 ).

The source is a $100 \mathrm{mCi} \mathrm{Am}^{241}$ with a $60 \mathrm{keV}$

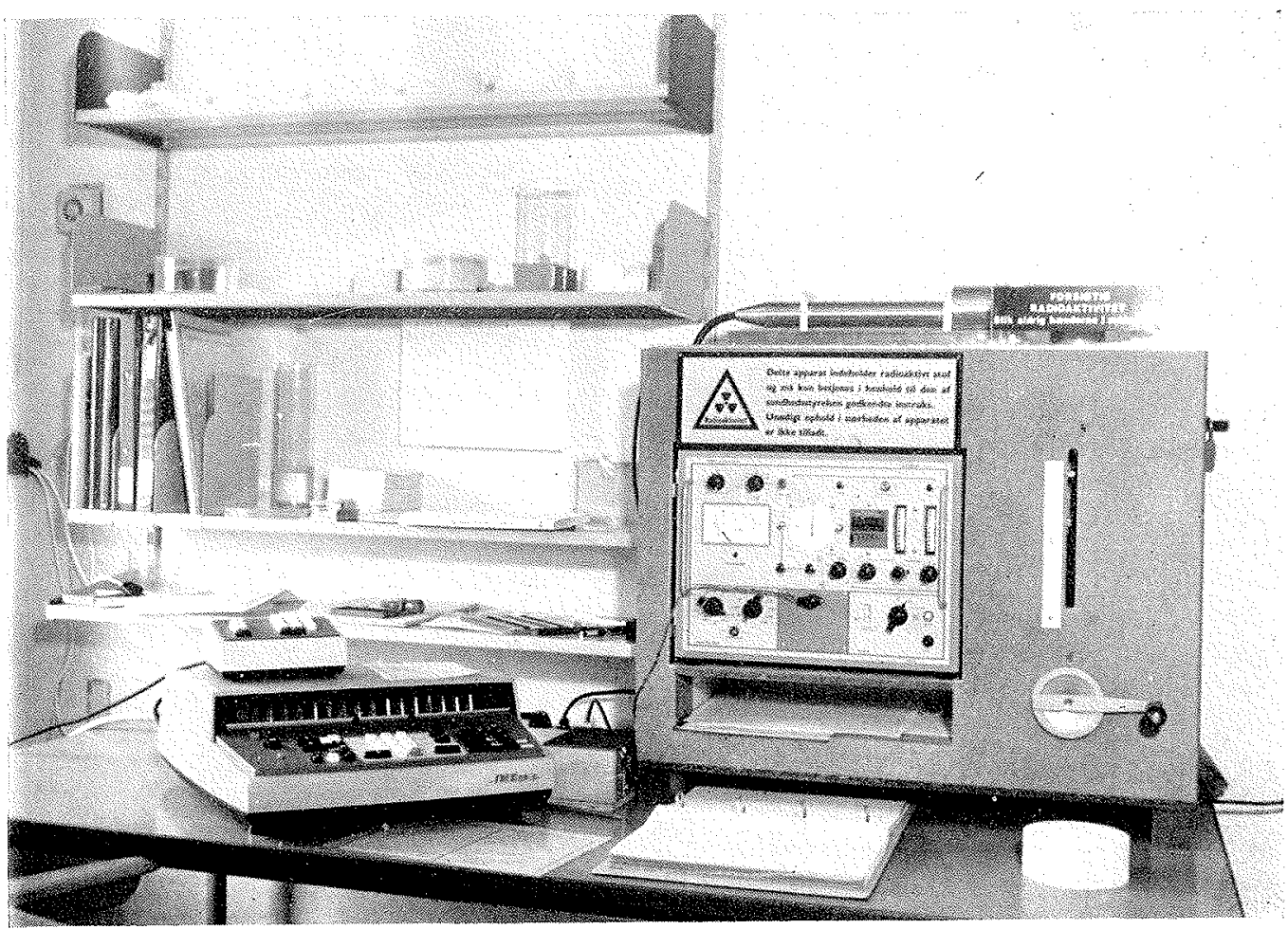

Fig. 1. To the right the gamma-ray-equipment with source, detector and BASC. To the left a desk calcularor with programming devices, for automatic calculation of water content. On the table one specimen. 


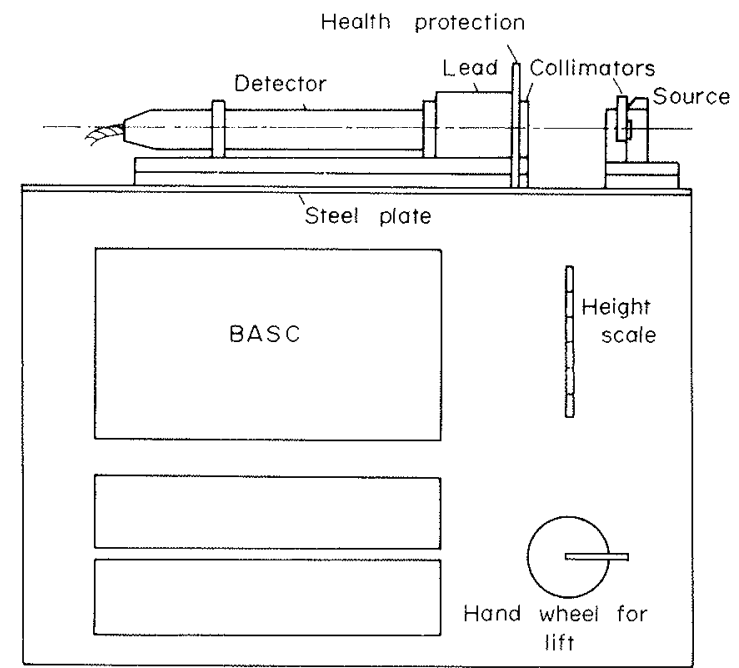

Front view

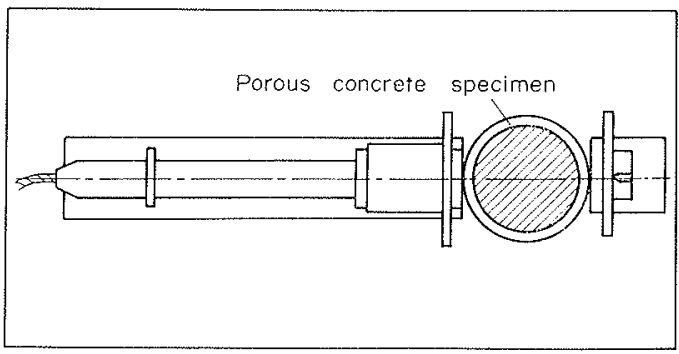

Seen from above

Fig. 2. Gamma-ray equipment.

gamma-ray emission. The emission is not strictly mono-energetic, but the greater part is of $60 \mathrm{keV}$, so formula (1) could be used. The half-life is 458 years, so there is no correction for decay. The source is mounted in a $5 \times 5 \times 4 \mathrm{~cm}$ brass enclosure with a $7 \mathrm{~mm}$ circular hole in the direction of the detector. For this source, $1 \mathrm{~cm}$ brass is sufficient for the purpose of health protection. The source housing has a movable slide with 3 collimators of different heights.

The detector is a NEA standard gamma scintillation detector with a $1^{\prime \prime} \times 1^{\prime \prime}$ ruggedized $\mathrm{NaI}$ crystal, photomultiplier and a transistorized preamplifier. The detector is shielded by a lead cylinder, which reduces the background radiation to $2 \cdot 2$ counts/sec. In the front of the detector is an interchangeable collimator with a hole. By changing the collimator it is possible to narrow or widen the area which is to be measured. Good collimation reduces the influence of the scattered rays. When a narrow beam is used, it is necessary to have the source and the detector mounted very accurately.

The detector is connected with a BASC radioactivity measuring instrument [5] with a high stability (against voltage and temperature variations) and a single channel pulse height analyser. The instrument has preset countscaler, linear and logarithmic count-ratemeter. Death-time is $5 \mu \mathrm{sec} /$ count. For the measurements we make it has a preset time device.

The equipment was supplied by the Danish Isotope Centre in Copenhagen in August 1971. The total cost was approx. D.kr. 50,000.

\section{CALIBRATION}

The calibration has been done with one set of collimators and gives a beam of about $5 \mathrm{~mm}$ in height and $10 \mathrm{~mm}$ in width. For other collimators or sources the following numerical values would not be the same. The intensity of the radiation beam without absorbing material $N_{0}$ had to be determined indirectly. By measuring $x, y$ and $(x+y) \mathrm{cm}$ brass the beam intensities are:

$$
\begin{aligned}
& \ln N_{x}=\ln N_{0}-(\mu \rho) \cdot x \\
& \ln N_{y}=\ln N_{0}-(\mu \rho) \cdot y \\
& \ln N_{x y}=\ln N_{0}-(\mu \rho) \cdot(x+y)
\end{aligned}
$$

where $(\mu \rho)$ is for brass. By substitution:

$$
\ln N_{0}=\ln N_{x}+\ln N_{y}-\ln N_{x y}
$$

The value of $\ln N_{0}$ was found to be $9.903, \sigma=$ 0.001 . The $(\mu \rho)$-value for glue and acryl is found by:

$$
\begin{aligned}
& \ln N_{1}=\ln N_{0}-(\mu \rho x)_{b}-(\mu \rho x)_{z} \\
& \ln N_{2}=\ln N_{0}-(\mu \rho x)_{b}
\end{aligned}
$$

and

$$
(\mu \rho x)_{z}=\ln N_{2}-\ln N_{1}
$$

where $z$ acryl or glue

$b$ brass

$N_{1}$ the intensity for the material $z$ and a standard brass of $1.5 \mathrm{~mm}$ (counts/sec)

$N_{2}$ the intensity for the standard brass (counts/sec).

The $1.5 \mathrm{~mm}$ brass is necessary to reduce the intensity of the rays.

( $\mu \rho$ ) for glue is $0.204 \mathrm{~cm}^{2} / \mathrm{g}, \sigma=0.001 \mathrm{~cm}^{2} / \mathrm{g}$

$(\mu \rho)$ for acryl is $0.215 \mathrm{~cm}^{2} / \mathrm{g}, \sigma=0.002 \mathrm{~cm}^{2} / \mathrm{g}$

The attenuation coefficient $\mu$ for water is determined by measuring on acryl tubes with and without water. Here, too, it was necessary to reduce the intensity by the $1.5 \mathrm{~mm}$ brass. For water we obtain from formula (7):

$$
\mu_{w}=\frac{\ln N_{2}-\ln N_{1}}{(\rho x)_{w}}
$$


where $N_{1}$ the intensity for water, acryl and brass (counts/sec)

$N_{2}$ the intensity for acryl and brass (counts/sec)

$x$ the inner diameter of the acryl tube.

The value of $\mu_{w}$ was found to be $0.1907 \mathrm{~cm}^{2} / \mathrm{g}$ with a standard deviation of $0.0014 \mathrm{~cm}^{2} / \mathrm{g}$. At $20^{\circ} \mathrm{C}$ the value of $(\mu x)_{w}$ is $0.191 \mathrm{~cm}^{-1}$. The theoretical value of $(\mu x)_{w}$, has been calculated by Grodstein [3] to be $0.204 \mathrm{~cm}^{-1}$. This calculation was made on the assumption that every Compton scattering event causes one gamma ray to be thrown out of the beam and therefore dismissed. In practice, it will be possible for gamma rays to reach the detector and be measured after one or more scattering events [4]. As the gamma rays which have been scattered may have sufficient energy, some of them will also be measured in the system. These rays increase the count rate $N$ in comparison to the theoretical case. Therefore the measured $\mu$-value will be less than the theoretical value. For measuring water content in porous concrete, it has been found that the $\mu$-value is dependent on the water content due to the increase in scattered radiation. This will be dealt with later.

The $\mu$-values of porous concrete have been found and calculated by using formula (1). The value is dependent on the dry density (see figure 3 ). This difference is also caused by the scattered radiation.

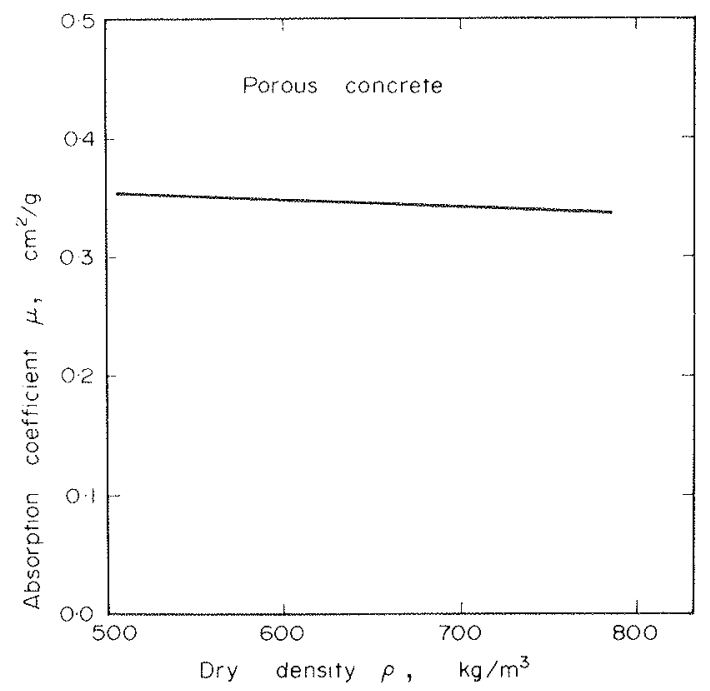

Fig. 3. The absorption coefficient plotted against the dry density for porous concrete.

\section{MEASUREMENTS OF HOMOGENEITY}

The test specimens have a cylindrical shape with a diameter of $121 \mathrm{~mm}$ and a thickness of $50 \mathrm{~mm}$.
The specimens are numbered, and the number side is always up, when the measurement is made.

For controlling the homogeneity of the porous concrete specimens in dry condition $\left(105^{\circ} \mathrm{C}\right.$ in hot box) the measurements are made at 6 angles $\left(0^{\circ}\right.$, $30^{\circ}, 60^{\circ}, 90^{\circ}, 120^{\circ}, 150^{\circ}$ ) from the source-detectorline and for each of these at 5 heights $(5,15,25,35$, $45 \mathrm{~mm}$ from the lower edge of the specimen to the centre of the radiation beam). This gives, for each specimen, 30 measured values of $N$ and $\ln N$ (see figure 4). The mean of $\ln N$ in a specimen is proportional to the density and therefore also the dry

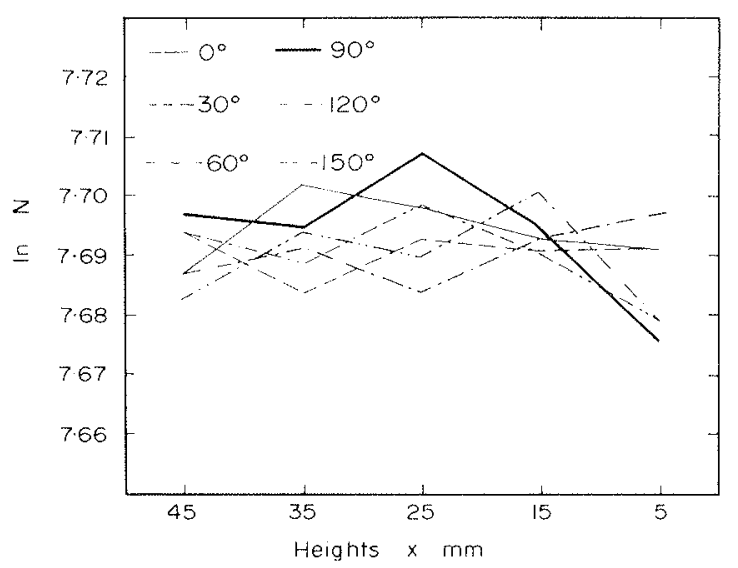

Fig. 4. The variation of the natural logarithm of the counting rate versus height and angle. The lines are

drawn between the measured values, 5 per angle.

weight of the specimen. The variations of the values of $\ln N$ in a specimen are equivalent to the variations in dry density. From the results it is possible to say that for each specimen there is a certain probability that the dry density in a random place is within certain limits from the mean density.

Figure 5 is an example of a specimen with a small density variation, and would be used in the experiments.

Figure 6 is an example of a specimen with too great a density variation, and is therefore not used in the experiment. It can be seen that the specimen has too great a density variation also apart from the stone at $35 \mathrm{~mm}^{\prime}$ height.

Figure 7 is an example of a specimen with an air bubble, and would therefore not be accepted.

For the time being we would accept a specimen if the standard derivation $\sigma$ were less than $4 \mathrm{~kg} / \mathrm{m}^{3}$.

\section{MEASUREMENTS OF MOISTURE CONTENT AND MOISTURE DISTRIBUTION}

The measurements of moisture content are made at one angle $\left(90^{\circ}\right)$ and in 9 or 5 heights (with 5 and $10 \mathrm{~mm}$ intervals). It is necessary to determine the 


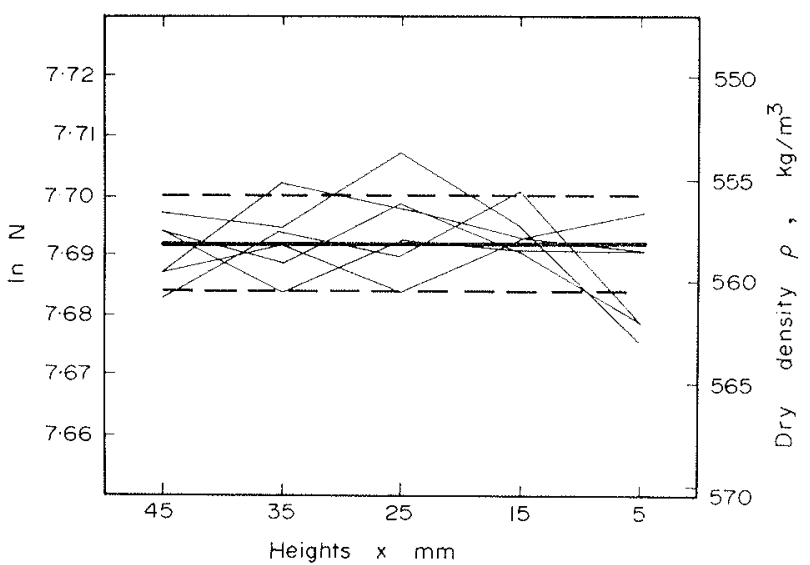

Fig. 5. The variation of the natural logarithn for one specimen. The same as figure 4. The equivalent densityvariations are also shown, and the mean value and the limits of standard derivation $\sigma$.

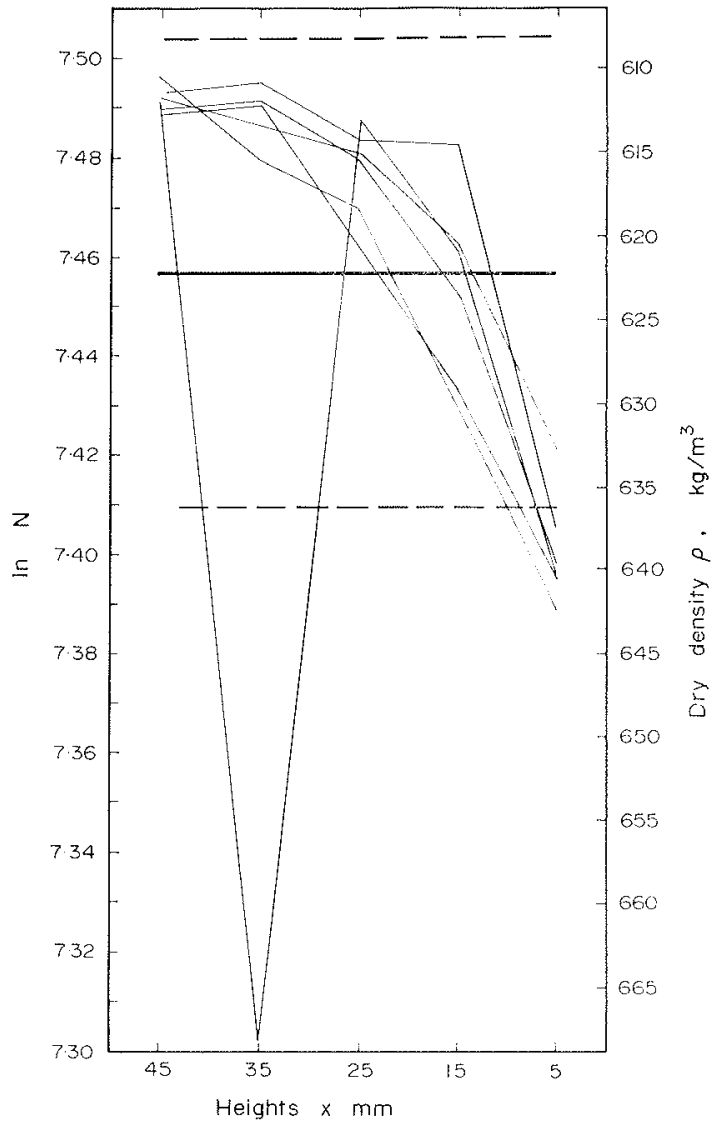

Fig. 6. The density variations, the mean value and the limits of standard derivation $\sigma$ for one specimen. The inhomogeneity at $35 \mathrm{~mm}$ height is caused by a stone.

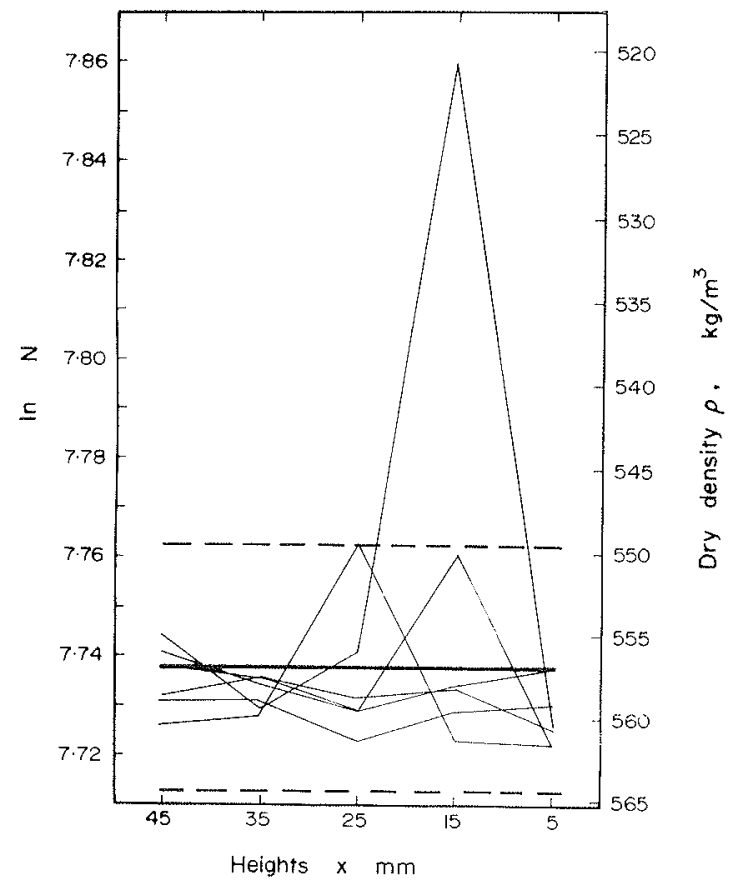

Fig. 7. The density variations, the mean value and limits of standard derivation $\sigma$ for one specimen. The inhomogeneity at $15 \mathrm{~mm}$ height is caused by an air bubble.

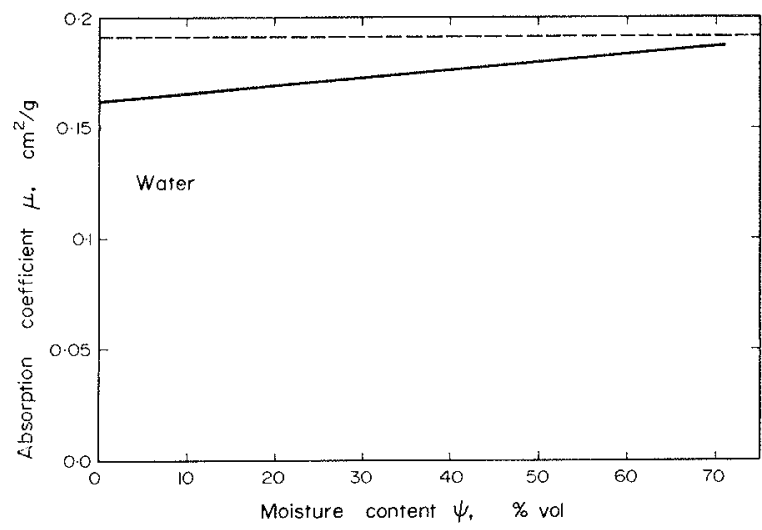

Fig. 8. The absorption coefficient of water plotted against the moisture content of porous concrete. The dotted line is the theoretical absorption coefficient for water. The other line gives the measured values. 
intensity of the beam in a dry material to get a zero-value of water content. This is done for each height. It is then possible to measure the intensity variations of the beam from the zero-value and, by calculation, to find the moisture content from

$$
\psi=\frac{\ln N_{0}-\ln N_{z}}{\mu \cdot x \cdot \rho}
$$

where $\psi$ moisture content $\left(\mathrm{cm}^{3} / \mathrm{cm}^{3}\right)$

$\mu$ absorption coefficient for water $\left(\mathrm{cm}^{2} / \mathrm{g}\right)$ $(0 \cdot 1907)$

$\rho$ density for water $\left(\mathrm{g} / \mathrm{cm}^{3}\right)(\sim 1)$

$x$ concrete thickness $(\mathrm{cm})(\sim 12 \cdot 15)$

$N_{0}$ intensity with no water (counts/sec)

$N_{z} \quad$ intensity with water (counts/sec)

The results of this calculation show a difference between the calculated value of moisture content and the moisture content found by weighing the specimen. This is explained by the fact that the attenuation coefficient $\mu$ for water is dependent on

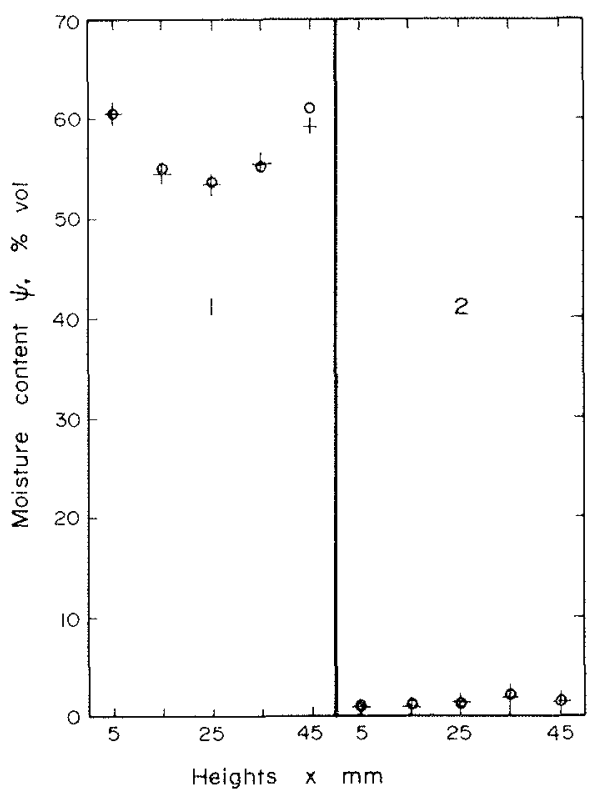

Fig. 9. Measurements of water content for 2 specimens measured one by one (circles), and with 0.15 mm plastic between (crosses). The measurements show almost no differences.

the attenuation material, in this case the mixture of water and porous concrete. This is because the amount of detected scattered radiation is greater at a higher density. The resulting $\mu$, which depends on moisture content, is found in figure 8 and is the first attempt at making a calibration curve, as we have not enough measurements. For the measurements we will make, it will always be possible to weigh the specimen and thereby determine the mean moisture content. Therefore we might calculate a new moisture distribution from the one originally measured, so that the mean moisture content is the same for the weighing method and the $\gamma$-ray measurement method.

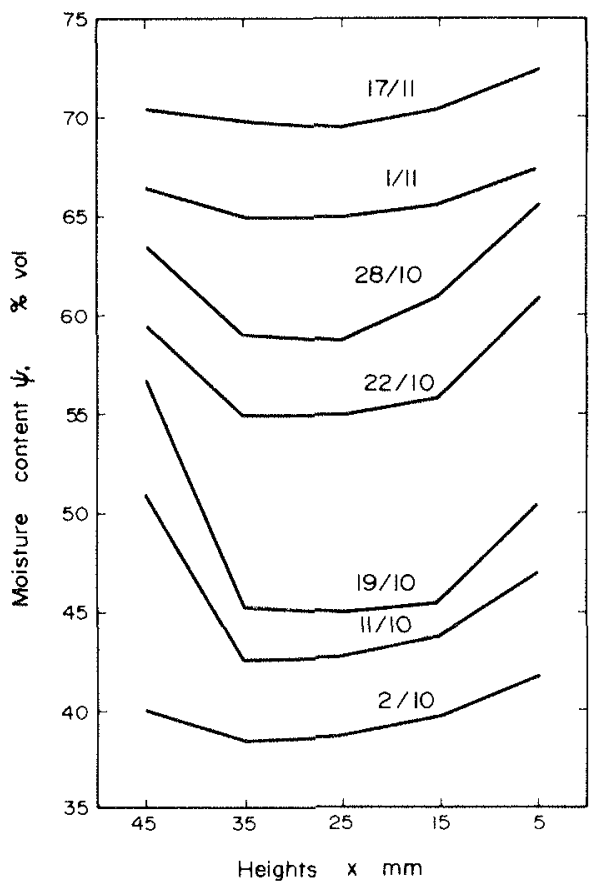

Fig. 10. The water content variations at different dates: The values are measured for water absorbing (from 21 st October in vacuum).

The edge of the specimen did not appear to exert any influence on the measurements, when they were made $5 \mathrm{~mm}$ or farther away from it, and when the specimen had been supplied with a $5 \mathrm{~mm}$ acryl plate on the top and bottom. A problem might arise if the radiation intensity were appreciably affected by moisture content outside the beam. This was investigated by placing two specimens one above the other with a $0.15 \mathrm{~mm}$ plastic sheet

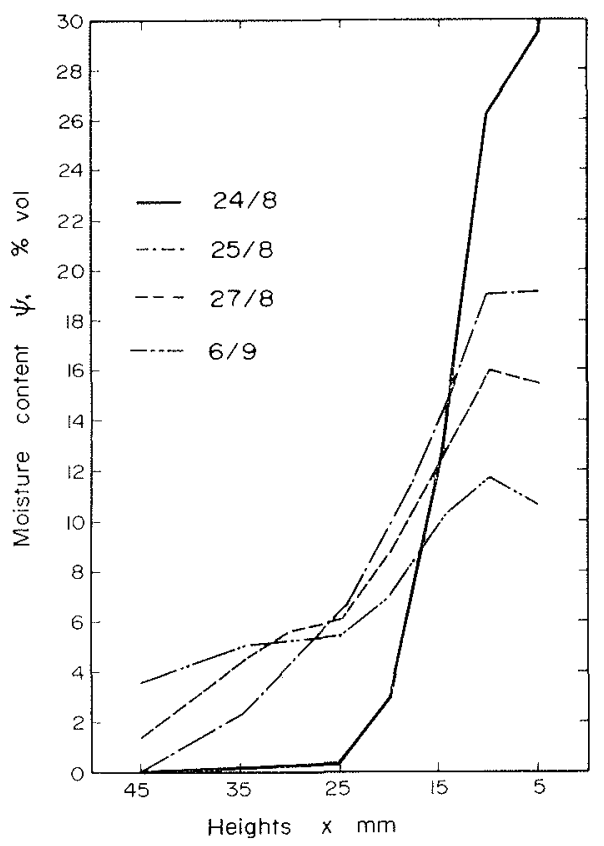

Fig. 11. The water content in the specimen at different dates. The mean water content is almost the same, but the water is redistributed. 
between. The result is shown in figure 9 , and almost no differences can be seen between the measurements performed this way and those performed with the specimens one by one. A variation in water content from 2 per cent to 60 per cent will normally not occur, which means that this effect can usually be disregarded.

Figure 10 gives an example of the absorbing of water in a specimen. The distribution shows that the water content is higher at the surface, as can be expected according to the theories for water flow.

Figure 11 shows an example of a specimen which has first been dipped in about $15 \mathrm{~mm}$ of water. The first measurements were made on the 24 th of August about 15 min after the specimen had been dipped in water. From this date the specimen had been closed so that the mean water content is almost the same. It can be seen that the water is redistributed so that the water content tends to be equal throughout the specimen.

\section{CONCLUSION}

The use of gamma-ray-attenuation on porous concrete for measuring the homogeneity and moisture content has fulfilled our expectations. As it is possible to obtain information of the homogeneity of the specimens, one can get better results from the moisture experiments, because all the specimens are nearly identical. Measurement of moisture content distributions can be made with good resolution, and it is shown that the beam is only slightly affected by moisture outside the beam area. When the calibration has been made thoroughly it is possible to obtain a good accuracy of the moisture content measurements.

\section{REFERENCES}

1. J. M. Davidson, J. W. BigGar and D. R. Nielsen, Gamma-radiation for measuring bulk density and transient water flow in porous materials. J. Geophys, Res. 68, 4777 (1963).

2. S. ElSNAB OlesEN, Evaporation and water transfer in relation to the surface structure and the water content of the ground. Laboratory for water-supply engineering, the Royal Veterinary and Agricultural College, Copenhagen. (1970) (in Danish).

3. G. W. Grodstern, X-ray attenuation coefficients from $10 \mathrm{keV}$ to $100 \mathrm{MeV}$. Natl. Bur. Stad. U.S., Circ. 583, April 30 (1957).

4. P. H. Groenevelt, J. G. De Swart and J. Cisler, Water content measurement with $60 \mathrm{keV}$ gamma ray attenuation. Symp. Soil Water, Grenoble (1969).

5. E. SOMER, The BASF Combined Soil Moisture/Density Gauge and other Moisture/ Density Equipment produced by NEA, Copenhagen. Int. Symp.: Radiometric Methods and Instruments for the Determination of Density and Moisture of Building Materials and Soils, Brno, Czechoslovakia, 29-31. October (1969).

La méthode d'atténuation par rayons gamma pour la détermination de la teneur en eau possède l'avantage d'être non-destructive et indépendante des gradients de température dans la matériau. Il est également possible de vérifier l'homogénéité des échantillons par cette méthode. Le Laboratoire d'Isolement Thermique possède un équipement avec une source de $100 \mathrm{mC} \mathrm{Am}^{241}$ pour les mesures sur le béton poreux. L'exposé donne un aperçu de la théorie pour l'atténuation par rayons gamma et le calibrage de l'équipement y compris les valeurs mesurées obtenues pour cet équipement. Finalement, quelques exemples sont présentés de mesures d'homogénéité et de teneur en eau de divers échantillons.

Das Verfahren der Gammastrahlendämpfung zur Ermittlung des Feuchtigkeitsgehalts hat den Vorteil, nicht zerstörend $z u$ wirken und unabhängig vom Temperaturgradienten in dem Material zu sein. Es ist ausserdem möglich, die Homogenität des Musters mit diesem Verfahren zu prüfen. Das Laboratorium für Wärmeisolation hat eine Anlage mit einer $100 \mathrm{mC} \mathrm{Am}^{241}$ Quelle für Messungen an porösem Beton. Der Bericht bringt einen Überlick über die Theorie der Gammastrahlendämpfung und der Kalibrierung der Anlage einschliesslich den, für die Anlage gefundenen Werten. Schliesslich werden einige Beispiele für Messungen der Homogenität und des Feuchtigkeitsgehalts verschiedener Muster gegeben. 
